\title{
Lower risk of postoperative arrhythmias in congenital heart surgery following intraoperative administration of magnesium
}

\author{
Dingchao He, MD, ${ }^{\mathrm{a}}$ Nimisha Aggarwal, MD, ${ }^{\mathrm{b}}$ David Zurakowski, MS, PhD, ${ }^{\mathrm{c}}$ Richard A. Jonas, MD, ${ }^{\mathrm{a}}$
} Charles I. Berul, MD, ${ }^{b}$ Sridhar Hanumanthaiah, MBBS, MS, ${ }^{b}$ and Jeffrey P. Moak, MD ${ }^{b}$

\section{ABSTRACT}

Objectives: Postoperative arrhythmias are common in children undergoing congenital heart surgery. We evaluated whether intraoperative administration of magnesium was associated with a reduced occurrence of specific postoperative arrhythmias, as has been described previously, or had a broader effect on multiple arrhythmia types, and whether there existed a dose-effect of intraoperative magnesium.

Methods: We used a historical prospective observational cohort study. Propensity score matching using logistic regression was applied to establish similar populations of treatment groups balanced on 5 important covariates.

Results: Based on propensity score-matched groups, magnesium $50 \mathrm{mg} / \mathrm{kg}$ administration was associated with a reduced odds of occurrence of postoperative arrhythmias: any arrhythmia (odds ratio $[\mathrm{OR}]=0.50, P<.001$ ), junctional ectopic tachycardia $(\mathrm{OR}=0.56, P=.004)$, accelerated junctional rhythm $(\mathrm{OR}=0.56, P=.089)$, atrial tachycardia $(\mathrm{OR}=0.48, P=.005)$, ventricular tachycardia $(\mathrm{OR}=0.52, P=.04)$, and atrioventricular block $(\mathrm{OR}=0.47$, $P=.03)$. The effect of magnesium on reducing the odds of occurrence of postoperative arrhythmias did not differ between $25 \mathrm{mg} / \mathrm{kg}$ versus $50 \mathrm{mg} / \mathrm{kg}$.

Conclusions: As many as one third of our patients undergoing congenital heart surgery had postoperative arrhythmias. Use of intraoperative magnesium was associated with a reduction in the odds of occurrence of all postoperative arrhythmias. Our results do not provide evidence that a greater dose of magnesium is associated with greater arrhythmia risk reduction. Despite the intraoperative use of magnesium, there continued to be a high residual incidence of postoperative arrhythmias, raising the question for studying new or additional agents. ( $\mathrm{J}$ Thorac Cardiovasc Surg 2018;156:763-70)

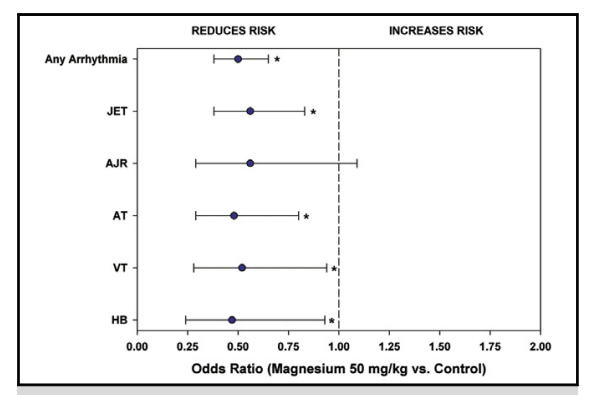

Odds ratios for postoperative arrhythmias. *Significant effect in reducing arrhythmia occurrence.

\section{Central Message}

Postoperative arrhythmias are common after congenital heart surgery. Intraoperative magnesium administration is associated with reduced occurrence of multiple arrhythmia types.

\section{Perspective}

Postoperative arrhythmias are common after congenital heart surgery. Intraoperative magnesium administration was associated with a reduced occurrence of all arrhythmias types and no differences were observed between the 2 doses studied. Despite the use of magnesium, there continued to be a high residual incidence of postoperative arrhythmias (18\%), raising the need for studying new or additional agents.

See Editorial Commentary page 771

See Editorial page 762
Postoperative arrhythmias such as junctional ectopic tachycardia (JET) are common in children undergoing congenital heart surgery (CHS) and are reported in 5\% to $38 \%$ of patients. ${ }^{1-6}$ JET delays postoperative recovery, prolongs

\footnotetext{
From the Divisions of ${ }^{\mathrm{a}}$ Cardiovascular Surgery and ${ }^{\mathrm{b}}$ Cardiology, Children's National Health System, Washington, DC; and ${ }^{\mathrm{c}}$ Departments of Anesthesiology and Surgery, Boston Children's Hospital, Harvard Medical School, Boston, Mass.

Received for publication Oct 14, 2017; revisions received Feb 21, 2018; accepted for publication April 5, 2018; available ahead of print May 16, 2018

Address for reprints: Jeffrey P. Moak, MD, Children's National Health System, 111 Michigan Ave, NW, Washington, DC 20010 (E-mail: jmoak@childrensnational. org)

$0022-5223 / \$ 36.00$

Copyright (c) 2018 by The American Association for Thoracic Surgery https://doi.org/10.1016/j.jtcvs.2018.04.044
}

cardiac intensive care unit (CICU) and hospital stays, and increases postoperative morbidity and mortality. Attention has been predominantly focused on postoperative JET, although evidence is lacking regarding an association between magnesium $(\mathrm{Mg})$ use and dose and the reduction in the occurrence of other postoperative arrhythmias after CHS.

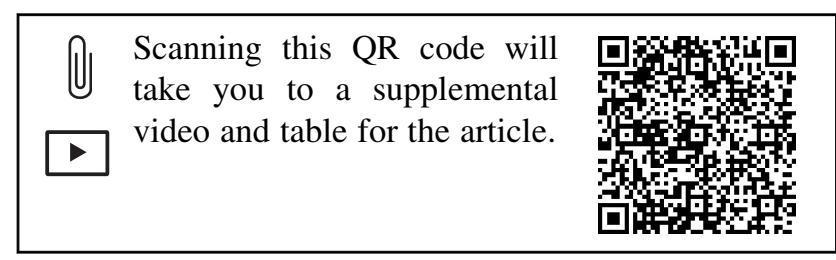




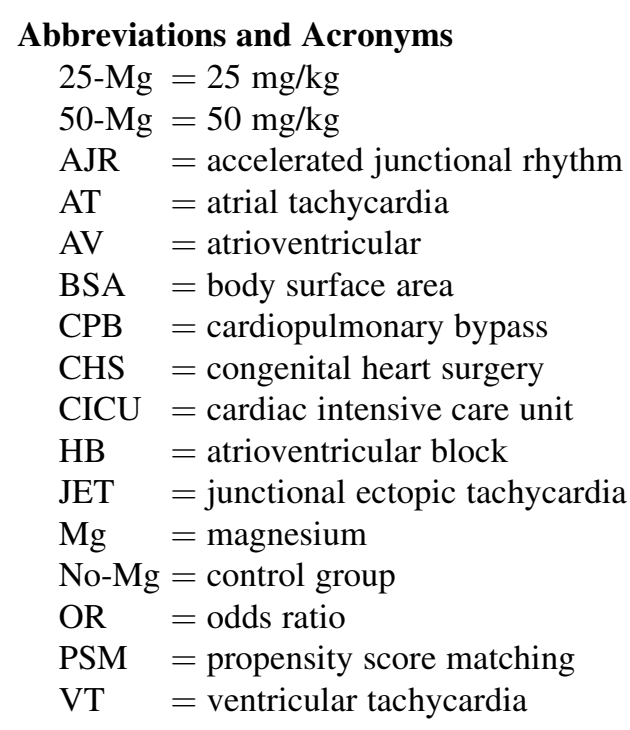

Mg has been the most widely studied agent used to lessen postoperative arrhythmias. The heterogeneous nature of these studies makes it difficult to ascertain the effect of $\mathrm{Mg}$ on postoperative arrhythmias other than postoperative JET and if Mg dose matters. Lee and colleagues performed a meta-analysis of 5 studies reporting on the use of $\mathrm{Mg}$ during or after CHS; 3 reports studied intraoperative and 2 postoperative $\mathrm{Mg}$ administration. ${ }^{7-12}$ The study populations were small and varied in size from 26 to 99 patients. The dose of administered $\mathrm{Mg}$ varied between 25 and $50 \mathrm{mg} / \mathrm{kg}$ intraoperatively. The method of $\mathrm{Mg}$ administration varied as either a single bolus $(30 \mathrm{mg} / \mathrm{kg})$ or a continuous infusion ( $4 \mathrm{mg} / \mathrm{kg} /$ hour). Evidence of arrhythmia suppression varied, and specific types of CHS assessed were limited in these studies. ${ }^{10} \mathrm{~A}$ recent meta-analysis of 35 studies in adult subjects undergoing cardiac surgery confirmed that $\mathrm{Mg}$ can reduce the occurrence of postoperative atrial fibrillation, but there was limited evidence to support $\mathrm{Mg}$ administration for prevention of other postoperative arrhythmias. ${ }^{13}$

We previously reported that intraoperative administration of $\mathrm{Mg}$ was associated with a lower risk for postoperative JET. ${ }^{14}$ Not defined in the medical literature and in an attempt to further expand our research, we wanted to study the impact of intraoperative $\mathrm{Mg}$ administration on postoperative arrhythmias other than postoperative JET and assess whether there existed a $\mathrm{Mg}$ dose-dependent effect. We reviewed our data on a large cohort of diverse patients with CHS who received either no $\mathrm{Mg}$ or 1 of 2 alternative doses $(25 \mathrm{mg} / \mathrm{kg}$ vs $50 \mathrm{mg} / \mathrm{kg})$ at the time of aortic crossclamp release. The purpose of this study was to evaluate (1) whether $\mathrm{Mg}$ administration was associated with a reduction in the occurrence of postoperative JET and other arrhythmia types and (2) whether there was evidence of a dose-effect of intraoperative $\mathrm{Mg}$ on the occurrence of postoperative arrhythmias.

\section{PATIENTS AND METHODS \\ Patient Population}

In total, 1871 patients who had undergone CHS with cardiopulmonary bypass (CPB) at our institute from 2005 to 2013 were selected and their medical records reviewed with approval from Children's National Health System Institutional Review Board (date and number of Institutional Review Board approval: October 1, 2013, Protocol 4188). Patients were excluded if they had (1) a history of preoperative arrhythmia, (2) incomplete or absent medical records, or (3) unclear description or no electrocardiographic evidence to assess postoperative arrhythmia. The electronic medical record, electrocardiograms, and telemetry records were reviewed from the time of entering the CICU until hospital discharge. The following clinical data were collected: date of surgery, sex, ethnicity, height, weight, body surface area (BSA), congenital heart disease type, congenital heart surgical procedure performed, dose of intraoperative $\mathrm{Mg}$ administered, occurrence of postoperative arrhythmic events, total surgical time, aortic crossclamp time, and CPB time.

\section{Intraoperative Mg Administration}

Patients with CHS were divided into 3 groups based on the dose of $\mathrm{Mg}$ administered intraoperatively: control group (no-Mg administration), $25-\mathrm{Mg}(25 \mathrm{mg} / \mathrm{kg})$, and $50-\mathrm{Mg}(50 \mathrm{mg} / \mathrm{kg})$. Mg dosage varied by era of surgery. In the no-Mg group, there were 750 cases randomly selected for study inclusion from a pool of 909 eligible cases out of a total of 1009 reviewed between 2005 and 2008. In the 25-Mg group, all 338 eligible cases were included from a total of 369 reviewed from May 2009 to July 2010. In the $50-\mathrm{Mg}$ group, all 783 eligible cases were included from a total of 810 reviewed from August 2010 to July 2013. Patients in either the 25-Mg and $50-\mathrm{Mg}$ group received a single bolus of $\mathrm{Mg}$ sulfate $(25 \mathrm{or} 50 \mathrm{mg} / \mathrm{kg}$ ) into the CPB circuit at the beginning of rewarming. The cardioplegic solution (Plegisol, Baxter, Deerfield, Ill), which contains $0.325 \%$ of Mg chloride, was given to all of the patients, according to our standard CPB protocol.

\section{Postoperative Arrhythmias}

Arrhythmias were classified into 5 categories as follows. (1) JET was defined as a supraventricular arrhythmia (wide or narrow QRS complex - same morphology as in sinus rhythm) with no preceding $\mathrm{P}$-wave at a rate that exceeded the normal junctional escape rate for age. The ventricular rate had to be more than $120 \mathrm{bpm}$. (2) If the ventricular rate was between 90 and $119 \mathrm{bpm}$, it was defined as accelerated junctional rhythm (AJR). (3) Atrial tachycardia (AT) was defined as a regular atrial rhythm that exceeded the underlying sinus rate and exhibited a sudden acceleration or rapid warm-up of rate with the P-wave morphology different from sinus rhythm/sinus tachycardia. (4) Ventricular tachycardia (VT) was defined as a sequence of 3 or more consecutive ventricular beats with a rate greater than $120 \mathrm{bpm}$ and included nonsustained and sustained VT. (5) Atrioventricular block (HB) was defined as atrioventricular (AV) conduction block that included second-degree and third-degree AV block. First-degree AV block was excluded. Some patients had multiple arrhythmia types and were included in each respective arrhythmia category. The duration of the arrhythmia had to be frequent and long enough to be documented on either cardiac telemetry or on an electrocardiogram. Other than for nonsustained periods of VT, all arrhythmias were only included if lasted for $>1$ minute or recurred frequently. All children were on telemetry for the full length of their hospitalization.

\section{Surgical Procedure Types}

Because of the diverse composition of the study group, we divided surgical procedure types into 5 groups: (1) conotruncal/ventricular septal 
defects, (2) single-ventricle anatomy, (3) atrial septal defect/pulmonary venous anomalies, (4) outflow obstruction defects, and (5) primary valvular heart defects or miscellaneous.

\section{Statistical Analysis}

Propensity score matching (PSM) was performed to balance covariates between treatment $(\mathrm{Mg})$ and control (no- $\mathrm{Mg}$ ) groups using multivariable logistic regression to derive the propensity scores and nearest neighbor matching based on a caliper width equal to 0.2 of the pooled standard deviation of the logit using 1 to 1 matching without replacement. ${ }^{15,16}$ This was done for low-dose $(25-\mathrm{Mg})$ as well as high-dose $(50-\mathrm{Mg}) \mathrm{Mg}$ to match controls to each of these $\mathrm{Mg}$ treatment groups. Five covariates previously shown to be associated with the occurrence of postoperative arrhythmias were used: age, weight, Aristotle score, cardiac diagnosis, and surgical time. The absolute standardized mean difference (d) was assessed to evaluate the quality of the matching in balancing the treatment and control groups. ${ }^{15,16}$ Conditional logistic regression was applied to compare the effects of each dose of $\mathrm{Mg}$ with the matched controls with respect to the incidence of any postoperative arrhythmia with each of the 5 specific arrhythmia types analyzed. Low- and high-dose $\mathrm{Mg}$ groups were also compared with the Mann-Whitney $U$ test for medians and the Fisher exact test for independent proportions.

Odds ratios (ORs) were computed to estimate the treatment effect with $95 \%$ confidence intervals with no-Mg controls as the reference group, and significance was determined with the Wald test in conditional logistic regression to account for the matched sets. Forest plots were constructed to illustrate effects of $\mathrm{Mg}$ in reducing risk of postoperative arrhythmia events compared with control, with a dashed vertical line at an OR of 1.00 denoting no difference. Statistical power was greater than $85 \%$ for detecting an OR of 0.50 in reducing postoperative arrhythmias for each $\mathrm{Mg}$ dose compared with control using logistic regression with an alpha level of 0.05 (nQuery Advisor version 7.0; Statistical Solutions, Cork,
Ireland). Statistical analysis was conducted with the Stata software package with PSMATCH2 module for matching (Stata Release 13, StataCorp, College Station, Tex). Two-tailed values of $P<.05$ were considered statistically significant. Overall arrhythmia incidence was the primary end point, and the individual rhythms were the secondary endpoints of the analysis.

\section{RESULTS \\ Patient Population}

The study population consisted of 1871 patients (no-Mg group, $\mathrm{n}=750 ; 25-\mathrm{Mg}, \mathrm{n}=338$; and $50-\mathrm{Mg}, \mathrm{n}=783$ ) from a total cohort of 2188 patients undergoing cardiac surgery during the study period (Figure 1 and Table E1). Patients were selected by using the criteria described in the Methods section. Of these, 307 paired patients were selected for PSM comparing no-Mg versus $25-\mathrm{Mg}$ and 540 paired subjects were selected comparing no-Mg versus $50-\mathrm{Mg}$. PSM resulted in a well-balanced study population with the absolute standardized mean differences between study groups $\leq 0.10$ on all matched covariates (Tables 1 and 2). Six hundred four of the 750 control patients were used for matching. Two hundred forty-three were matched with both the $25-\mathrm{Mg}$ and $50-\mathrm{Mg}$ groups.

\section{No-Mg Versus 25-Mg}

No differences were noted in the baseline demographics between the 2 study groups specifically for age, weight, BSA, sex, race, type of cardiac defect, Aristotle score, aortic crossclamp time, CPB time, and total surgical time (Table 1).

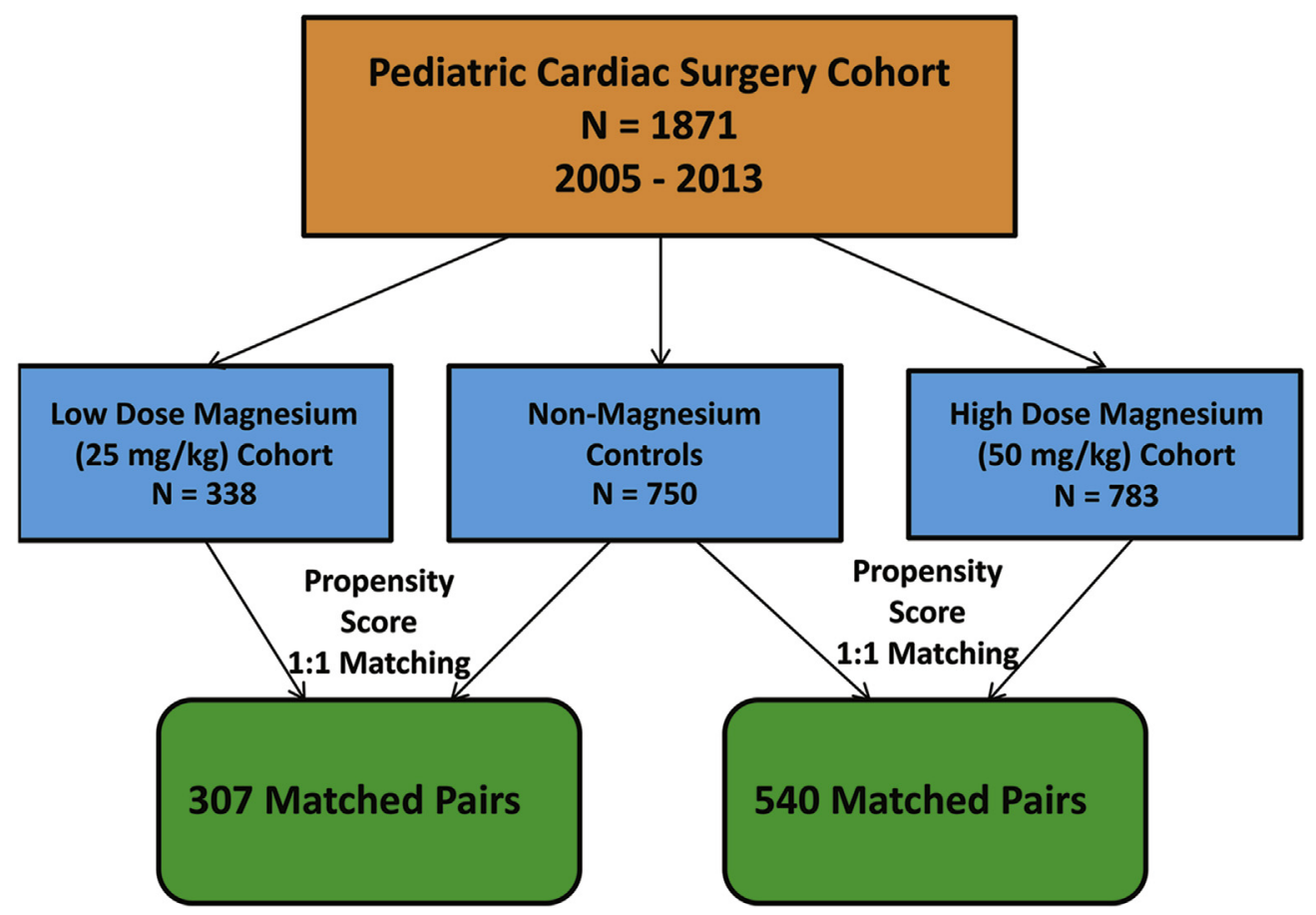

FIGURE 1. Study population. The study population consisted of 1871 patients (no-Mg group, $\mathrm{n}=750 ; 25-\mathrm{Mg}, \mathrm{n}=338 ;$ and $50-\mathrm{Mg}, \mathrm{n}=783$ ). Three hundred seven paired patients were selected for propensity-score matching comparing no-Mg versus $25-\mathrm{Mg}$, and 540 paired patients were selected comparing no- $\mathrm{Mg}$ versus $50-\mathrm{Mg}$. Some control patients were used for matching in both the $25-\mathrm{Mg}$ and $50-\mathrm{Mg}$ group comparisons. $25-\mathrm{Mg}, 25 \mathrm{mg} / \mathrm{kg}$; $50-\mathrm{Mg}, 50 \mathrm{mg} / \mathrm{kg}$. 
TABLE 1. Baseline characteristics for propensity score-matched controls and low-dose magnesium treatment

\begin{tabular}{|c|c|c|c|c|}
\hline Variable & $\begin{array}{l}\text { No-Mg control group } \\
\qquad(\mathbf{n}=\mathbf{3 0 7})\end{array}$ & $\begin{array}{c}\text { 25-Mg } \\
(\mathbf{n}=\mathbf{3 0 7})\end{array}$ & $P$ value & $d$ statistic \\
\hline Age, mo & $7(4-26)$ & $6(2-22)$ & .18 & 0.10 \\
\hline Weight, kg & $6.6(4.3-11.7)$ & $6.0(3.9-10.3)$ & .15 & 0.10 \\
\hline $\mathrm{BSA}, \mathrm{m}^{2}$ & $0.35(0.26-0.52)$ & $0.32(0.24-0.48)$ & .11 & 0.09 \\
\hline Male sex, n (\%) & $177(58)$ & $160(52)$ & .20 & 0.11 \\
\hline Race, n (\%) & & & .84 & \\
\hline White & $135(44)$ & $130(42)$ & & 0.03 \\
\hline African American & $81(26)$ & $93(30)$ & & 0.09 \\
\hline Hispanic & $46(15)$ & $43(14)$ & & 0.03 \\
\hline Asian & $13(4)$ & $10(3)$ & & 0.05 \\
\hline Other & $32(10)$ & $31(10)$ & & 0.02 \\
\hline Cardiac defect, n (\%) & & & .53 & \\
\hline Conotruncal/VSD & $125(41)$ & $139(45)$ & & 0.09 \\
\hline Single ventricle & $107(35)$ & $107(35)$ & & 0.01 \\
\hline Atrial septal defect & $20(7)$ & $20(7)$ & & 0.01 \\
\hline Outflow obstruction & $29(9)$ & $19(6)$ & & 0.10 \\
\hline Miscellaneous/valve & $26(8)$ & $22(7)$ & & 0.05 \\
\hline Aristotle score, $\mathrm{n}(\%)$ & & & .57 & 0.05 \\
\hline 1 or 2 & $186(61)$ & $178(58)$ & & \\
\hline 3 or 4 & $121(39)$ & $129(42)$ & & \\
\hline Crossclamp time, min & $39(26-50)$ & $36(21-49)$ & .17 & 0.10 \\
\hline $\mathrm{CPB}$ time, $\min$ & $82(65-105)$ & $82(64-106)$ & .99 & 0.02 \\
\hline Surgical time, $\min$ & 200 (174-240) & 205 (170-240) & .98 & 0.03 \\
\hline
\end{tabular}

Continuous data are represented by the median (interquartile range). $N o-M g$, No magnesium given; $25-M g, 25 \mathrm{mg} / \mathrm{kg} ; d$, standardized mean difference; $B S A$, body surface area; $V S D$, ventricular septal defect; $C P B$, cardiopulmonary bypass.

25-Mg significantly reduced the odds of any postoperative arrhythmia $(\mathrm{OR}=0.40, P<.001)$, postoperative JET (OR $=0.45, P=.003)$, postoperative AJR $(\mathrm{OR}=0.40$, $P=.037)$, and postoperative AT $(\mathrm{OR}=0.32, P=.003)$ (Table 3 and Figure 2). The effect of $25-\mathrm{Mg}$ on postoperative $\mathrm{VT}(\mathrm{OR}=0.81, P=.655)$ and $\mathrm{HB}(\mathrm{OR}=0.76, P=.492)$ was not significant (Table 3 and Figure 2, $A$ ).

\section{No-Mg Versus 50-Mg}

No differences were noted in the baseline demographics between the 2 study groups specifically for age, weight, BSA, sex, race, type of cardiac defect, Aristotle score, aortic crossclamp time, CPB time, and total surgical time (Table 2). 50-Mg significantly decreased the occurrence of any postoperative arrhythmia $(\mathrm{OR}=0.50, P<.001)$, postoperative JET $(\mathrm{OR}=0.56, P=.004)$, postoperative AJR $(\mathrm{OR}=0.56, P=.089)$, postoperative AT $(\mathrm{OR}=0.48, P=.005)$, postoperative VT $(\mathrm{OR}=0.52$, $P=.040)$, and HB (OR $=0.47, P=.03$ ) (Table 4 and Figure 2, B).

\section{5-Mg Versus 50-Mg}

No differences were noted in the OR of effect between 25- $\mathrm{Mg}$ and $50-\mathrm{Mg}$ on any postoperative arrhythmia $(\mathrm{OR}=1.23, P=.285)$, postoperative $\mathrm{JET}(\mathrm{OR}=1.08$,
$P=.792)$, postoperative AJR (OR $=1.22, P=.662)$, postoperative AT $(\mathrm{OR}=1.27, P=.551)$, postoperative $\mathrm{VT}(\mathrm{OR}=0.95, P=.897)$, and $\mathrm{HB}(\mathrm{OR}=0.73$, $P=$.466) (Table 5).

Baseline characteristics of the $25-\mathrm{Mg}$ and $50-\mathrm{Mg}$ treatment propensity-matched groups were compared with the Pearson $\chi^{2}$ analysis and Mann-Whitney $U$ tests. No statistical differences were noted in 9 of 10 analyzed variables: age, weight, BSA, aortic crossclamp time, CBP time, surgical time, sex, race, and Aristotle score. Overall distribution of specific cardiac defects showed some variation. For example, the composition of singleventricle patients to the total $25-\mathrm{Mg}$ group versus the $50-\mathrm{Mg}$ group was $35 \%$ versus $24 \%$. In contrast, the composition of conotruncal/VSD subjects to the $25-\mathrm{Mg}$ versus $50-\mathrm{Mg}$ groups was similar, $45 \%$ versus $49 \%$.

\section{Residual Arrhythmia Risk}

Despite the benefit of intraoperative administration of $\mathrm{Mg}$, there continued to be a fairly high occurrence of postoperative arrhythmias (total [18\%], postoperative JET [8\%], AJR [3\%], AT [4\%], VT [3\%], and HB [3\%]) (Table 5).

Some patients had multiple arrhythmias and were counted in each of the arrhythmia groups. Among all unique No-Mg patients $(\mathrm{n}=604$ controls), the incidence of 
TABLE 2. Baseline characteristics for propensity score-matched controls and high-dose magnesium treatment

\begin{tabular}{|c|c|c|c|c|}
\hline Variable & $\begin{array}{l}\text { No-Mg control group } \\
\qquad(\mathrm{n}=540)\end{array}$ & $\begin{array}{c}50-\mathrm{Mg} \\
(\mathrm{n}=540)\end{array}$ & $P$ value & $d$ statistic \\
\hline Age, mo & $6(2-25)$ & $5(2-24)$ & .80 & 0.01 \\
\hline Weight, kg & $6.1(4.0-10.9)$ & $5.7(4.0-11.4)$ & .95 & 0.01 \\
\hline $\mathrm{BSA}, \mathrm{m}^{2}$ & $0.33(0.24-0.50)$ & $0.31(0.25-0.51)$ & .97 & 0.01 \\
\hline Male sex, n (\%) & $287(53)$ & $278(52)$ & .63 & 0.03 \\
\hline Race, n (\%) & & & .12 & \\
\hline White & $223(41)$ & $232(43)$ & & 0.05 \\
\hline African American & $161(30)$ & $163(30)$ & & 0.01 \\
\hline Hispanic & $76(14)$ & $52(10)$ & & 0.10 \\
\hline Asian & $21(4)$ & $17(3)$ & & 0.04 \\
\hline Other & $59(11)$ & $76(14)$ & & 0.09 \\
\hline Cardiac defect, n $(\%)$ & & & .80 & \\
\hline Conotruncal/VSD & $274(51)$ & $263(49)$ & & 0.04 \\
\hline Single ventricle & $112(21)$ & $129(24)$ & & 0.08 \\
\hline Atrial septal defect & $59(11)$ & $55(10)$ & & 0.02 \\
\hline Outflow obstruction & $45(9)$ & $42(8)$ & & 0.02 \\
\hline Miscellaneous/valve & $50(9)$ & $51(9)$ & & 0.01 \\
\hline Aristotle score, n (\%) & & & .76 & 0.02 \\
\hline 1 or 2 & $319(59)$ & $313(58)$ & & \\
\hline 3 or 4 & $221(41)$ & $227(42)$ & & \\
\hline Crossclamp time, min & $40(28-54)$ & $38(22-55)$ & .10 & 0.10 \\
\hline CPB time, $\min$ & $82(65-105)$ & $80(64-110)$ & .85 & 0.05 \\
\hline Surgical time, min & $208(187-242)$ & $210(180-240)$ & .84 & 0.01 \\
\hline
\end{tabular}

multiple arrhythmias was 31 of $604(5.1 \%)$, which was significantly greater compared with 19 of $847(2.2 \%)$ $25-\mathrm{Mg}$ or $50-\mathrm{Mg}$ patients $(P=.003)$.

\section{DISCUSSION}

Postoperative arrhythmias impact the recovery of patients from congenital cardiac surgery, increase duration of intubation and CICU stay, and prolong total time in the hospital. Postoperative JET is the most common arrhythmia seen in children after open-heart surgery, with an average incidence of $14.3 \%{ }^{6}$ The frequency of other postoperative arrhythmias has not been as well documented and appears to vary among different surgical centers. In the current study, we observed in our control group that AT was the second most common postoperative arrhythmia $(8.3 \%)$, followed by AJR (4.8\%), VT (5\%), and HB (4.5\%). Dittrich and colleagues ${ }^{9}$ reported a similar occurrence rate of JET $(10.6 \%)$, AT $(10.6 \%)$, and HB (3\%). In the postoperative series published by Delaney and colleagues, ${ }^{17}$ the rate of postoperative JET was $8.5 \%$, complete HB was $3.7 \%$, and VT was $2.1 \%$. Talwar and colleagues ${ }^{18}$ observed a lower occurrence rate for postoperative JET (3.5\%) and supraventricular tachycardia $(2.5 \%)$.

The potential benefit of $\mathrm{Mg}$ in reducing the occurrence of postoperative arrhythmias depends on the underlying mechanism responsible for their individual occurrence. ${ }^{19}$ The risk factor profile for occurrence of postoperative JET seems best associated with measures of myocardial

TABLE 3. Incidence of postoperative arrhythmias for controls and low-dose magnesium treatment

\begin{tabular}{|c|c|c|c|c|c|c|}
\hline Event, n (\%) & Total $(n=614)$ & Control group $(\mathbf{n}=\mathbf{3 0 7})$ & 25-Mg $(\mathrm{n}=307)$ & Odds ratio* & $95 \% \mathrm{CI}$ & $P$ value \\
\hline Any arrhythmia & $147(24)$ & $98(32)$ & $49(16)$ & 0.40 & $0.28-0.60$ & $<.001 \dagger$ \\
\hline JET & $72(12)$ & $48(16)$ & $24(8)$ & 0.45 & $0.27-0.76$ & $.003 \dagger$ \\
\hline AJR & $24(4)$ & $17(6)$ & $7(2)$ & 0.40 & $0.17-0.93$ & $.037 \dagger$ \\
\hline AT & $39(6)$ & $29(9)$ & $10(3)$ & 0.32 & $0.15-0.68$ & $.003 \dagger$ \\
\hline VT & $20(3)$ & $11(4)$ & $9(3)$ & 0.81 & $0.33-1.95$ & .655 \\
\hline $\mathrm{HB}$ & $23(4)$ & $13(4)$ & $10(3)$ & 0.76 & $0.35-1.67$ & .492 \\
\hline
\end{tabular}

$25-M g, 25 \mathrm{mg} / \mathrm{kg} ; C I$, confidence interval; JET, junctional ectopic tachycardia; AJR, accelerated junctional rhythm; AT, atrial tachycardia; VT, ventricular tachycardia; $H B$, atrioventricular block. *Reference group $=$ control group. $\dagger$ Statistically significant treatment effect in reducing odds of arrhythmia occurrence. 

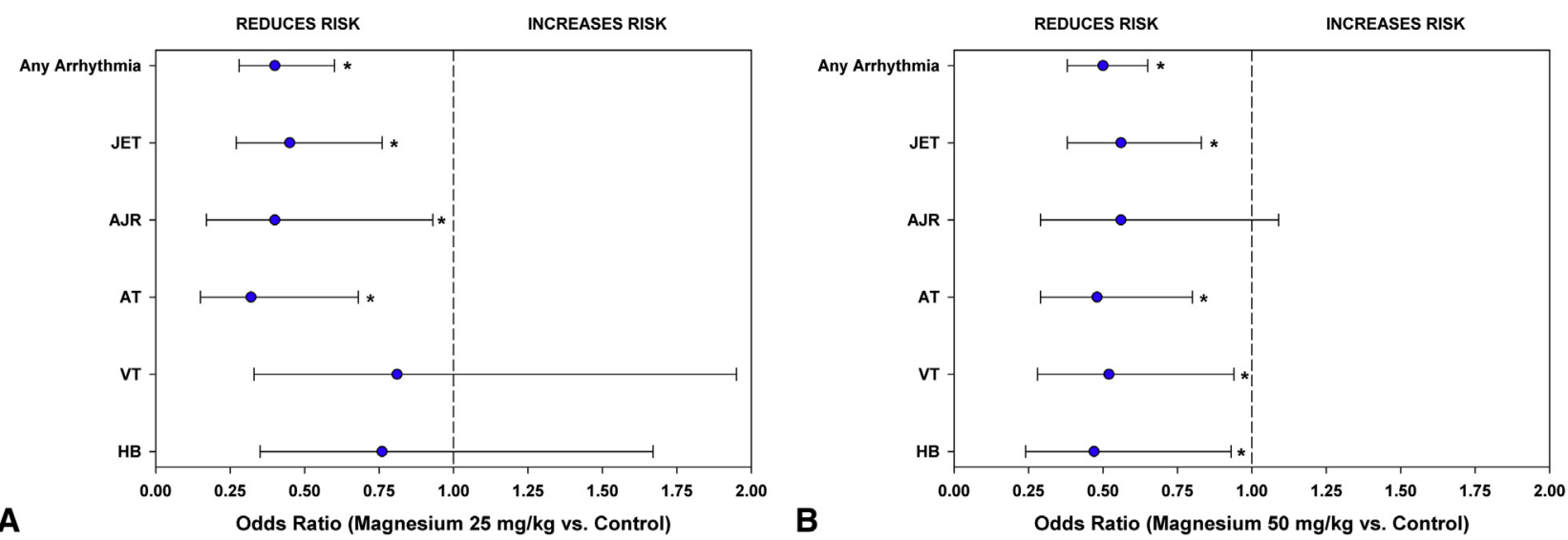

FIGURE 2. A, Forest plots depicting the odds ratios for postoperative arrhythmias, no-MG versus $25-\mathrm{Mg}$. 25-Mg significantly reduced the odds of occurrence of any postoperative arrhythmia $(\mathrm{OR}=0.40, P<.001)$, postoperative JET ( $\mathrm{OR}=0.45, P=.003)$, postoperative AJR $(\mathrm{OR}=0.40, P=.037)$, and postoperative AT $(\mathrm{OR}=0.32, P=.003)$. The effect on postoperative $\mathrm{VT}(\mathrm{OR}=0.81, P=.655)$ and $\mathrm{HB}(\mathrm{OR}=0.76, P=.492)$ was not significant. *Statistically significant treatment effect in reducing arrhythmia. B, Forest plots depicting the odds ratios for postoperative arrhythmias, no-MG versus 50-MG. $50-\mathrm{Mg}$ significantly decreased the occurrence of any postoperative arrhythmia ( $\mathrm{OR}=0.50, P<.001$ ), postoperative JET (OR $=0.56, P=.004)$, postoperative AJR $(\mathrm{OR}=0.56, P=.089)$, postoperative AT $(\mathrm{OR}=0.48, P=.005)$, postoperative VT $(\mathrm{OR}=0.52, P=.04)$, and $\mathrm{HB}(\mathrm{OR}=0.47, P=.03)$. *Statistically significant treatment effect in reducing arrhythmia. $O R$, Odds ratio; JET, junctional ectopic tachycardia; AJR, accelerated junctional rhythm; $A T$, atrial tachycardia; $V T$, ventricular tachycardia; $H B$, atrioventricular block; $25-M g, 25 \mathrm{mg} / \mathrm{kg} ; 50-M g, 50 \mathrm{mg} / \mathrm{kg}$.

ischemic/reperfusion injury incurred during the operative period. The underlying substrate for postoperative AT seems more related to atrial inflammation. Colchicine, an anti-inflammatory agent, has been demonstrated to decrease the odds of occurrence of postoperative atrial fibrillation by $52 \%$ in adult patients undergoing heart surgery. ${ }^{20}$ The etiology of postoperative HB may be multifactorialischemic/reperfusion injury of the conduction system and mechanical trauma to the AV node-His bundle conduction axis.

$\mathrm{Mg}$ has been used in cardiac surgery to reduce postoperative arrhythmias for many years. ${ }^{21,22}$ Despite this, few data have been published on the key questions of (1) whether there is a dose-dependent relationship between $\mathrm{Mg}$ administration and postoperative arrhythmia occurrence and (2) whether the effect of $\mathrm{Mg}$ is arrhythmia-specific. Studies have reported using varying doses of $\mathrm{Mg}$, assessing its effect mostly on postoperative JET and ventricular fibrillation, and in limited congenital heart disease subsets. In the present study, we assessed the relationship between alternative doses of $\mathrm{Mg}$ (25 and $50 \mathrm{mg} / \mathrm{kg}$ ) administered at the time of aortic crossclamp release and 5 postoperative arrhythmia subtypes in a diverse population of congenital heart diseases undergoing varying complexity levels of surgical repair.

Our data provide evidence that use of $\mathrm{Mg}$ is associated with a lower occurrence of all types of postoperative arrhythmias, with a statistically significantly lower risk of postoperative JET, AJR, and AT and borderline lower risks of postoperative VT and postoperative HB. There was little evidence of a dose-response effect.

It has been documented in clinical trials that $\mathrm{Mg}$ can reduce the occurrence of postoperative JET. ${ }^{8,9,14}$ A previously reported study of 99 patients by Manrique and colleagues $^{8}$ suggested a dose-dependent effect of $\mathrm{Mg}$ administration with the effect greater at $50-\mathrm{Mg}$ rather than $25-\mathrm{Mg}$. These investigators reported that following a dose of $50-\mathrm{Mg}$, the incidence of postoperative JET was zero.

TABLE 4. Incidence of postoperative arrhythmias for controls and high-dose magnesium treatment

\begin{tabular}{|c|c|c|c|c|c|c|}
\hline Event, n (\%) & Total $(n=1080)$ & Control group $(n=540)$ & $50-\mathrm{Mg}(\mathrm{n}=540)$ & Odds ratio* & $95 \%$ CI & $P$ value \\
\hline Any arrhythmia & $274(25)$ & $172(32)$ & $102(19)$ & 0.50 & $0.38-0.65$ & $<.001 \dagger$ \\
\hline JET & $120(11)$ & $75(14)$ & $45(8)$ & 0.56 & $0.38-0.83$ & $.004 \dagger$ \\
\hline AJR & $41(4)$ & $26(5)$ & $15(3)$ & 0.56 & $0.29-1.09$ & .089 \\
\hline AT & $66(6)$ & $44(8)$ & $22(4)$ & 0.48 & $0.29-0.80$ & $.005 \dagger$ \\
\hline VT & $43(4)$ & $28(5)$ & $15(3)$ & 0.52 & $0.28-0.94$ & $.04 \dagger$ \\
\hline HB & $40(4)$ & $27(5)$ & $13(2)$ & 0.47 & $0.24-0.93$ & $.03 \dagger$ \\
\hline
\end{tabular}

$50-M g, 50 \mathrm{mg} / \mathrm{kg} ; C I$, confidence interval; $J E T$, junctional ectopic tachycardia; $A J R$, accelerated junctional rhythm; $A T$, atrial tachycardia; $V T$, ventricular tachycardia; $H B$, atrioventricular block. ${ }^{*}$ Reference group $=$ control group. $\nmid$ Statistically significant treatment effect in reducing odds of arrhythmia occurrence. 
TABLE 5. Incidence of postoperative arrhythmias for low-dose and high-dose magnesium treatment

\begin{tabular}{|c|c|c|c|c|c|c|}
\hline Event, n (\%) & Total $(n=847)$ & $25-\mathrm{Mg}(\mathrm{n}=307)$ & $50-\mathrm{Mg}(\mathrm{n}=540)$ & Odds ratio* & $95 \%$ CI & $\boldsymbol{P}$ value ${ }^{\dagger}$ \\
\hline Any arrhythmia & $151(18)$ & 49 (16) & 102 (19) & 1.23 & $0.85-1.78$ & .285 \\
\hline JET & $69(8)$ & $24(8)$ & $45(8)$ & 1.08 & $0.64-1.79$ & .792 \\
\hline AJR & $22(3)$ & $7(2)$ & $15(3)$ & 1.22 & $0.49-3.03$ & .662 \\
\hline AT & $32(4)$ & $10(3)$ & $22(4)$ & 1.27 & $0.59-2.70$ & .551 \\
\hline VT & $24(3)$ & $9(3)$ & $15(3)$ & 0.95 & $0.41-2.17$ & .897 \\
\hline HB & $23(3)$ & $10(3)$ & $13(2)$ & 0.73 & $0.32-1.69$ & .466 \\
\hline
\end{tabular}

$25-M G, 25 \mathrm{mg} / \mathrm{kg} ; 50-M g, 50 \mathrm{mg} / \mathrm{kg} ; C I$, confidence interval; JET, junctional ectopic tachycardia; $A J R$, accelerated junctional rhythm; $A T$, atrial tachycardia; $V T$, ventricular tachycardia; $H B$, atrioventricular block. *Reference group $=25-\mathrm{Mg}$. $\dagger$ No statistically significant differences between high dose and low dose in the incidence of arrhythmias.

Dorman and colleagues ${ }^{11}$ reported in a series of 28 patients that the intraoperative administration of $30-\mathrm{Mg}$ resulted in no postoperative JET. Our study, based on hundreds of patients with PSM at 2 different doses of $\mathrm{Mg}$ to minimize any selection bias and with a much broader diversity of congenital heart diseases, was not able to confirm these early observations. Postoperative JET still occurred despite the intraoperative administration of $50-\mathrm{Mg}(8 \%$ incidence, 45 of 540 patients).

It has been controversial whether $\mathrm{Mg}$ can be used for prevention of postoperative AT or atrial fibrillation. All studies addressing this issue have focused on the adult cardiac surgical population. ${ }^{23-26}$ One study demonstrated a dose-effect of $\mathrm{Mg}$ in postoperative atrial fibrillation reduction $(60-100 \mathrm{mg} / \mathrm{kg})$, and others no effect of $\mathrm{Mg}$ in reducing the occurrence of postoperative atrial fibrillation. ${ }^{27,28}$ Our current data suggest that $\mathrm{Mg}$ use is associated with a $\sim 50 \%$ reduction in the odds of postoperative AT. This finding surprised us, given that the underlying electrophysiological substrate may differ from postoperative JET.

Aortic crossclamp time is an important risk factor in the development of postoperative arrhythmia, especially for JET, HB, and VT. Ischemia and reperfusion injury plays a critical role in this process. ${ }^{29}$ During CHS, the ischemic and reperfusion injury associated with aortic crossclamp can have detrimental effects on the sinus node, AV node, and conduction system, facilitating postoperative arrhythmia, especially in the neonate and infant because of immature and unstable recovery mechanisms. ${ }^{29,30}$

Despite the intraoperative administration of $\mathrm{Mg}$, there continues to be a high incidence of postoperative arrhythmias. Our findings beg the question for studying new or additional agents administered as a sole medication or combined with $\mathrm{Mg}$ to further reduce the occurrence of postoperative arrhythmias. For example, Amrousy and colleagues ${ }^{31}$ found that intravenous amiodarone administered at the time of induction of anesthesia for CHS lowered the incidence of postoperative JET from $28.9 \%$ to $9.2 \%$. Mahmoud and colleagues ${ }^{32}$ noted the incidence of postoperative JET was decreased after the preoperative administration of propranolol from $38 \%$ to $21 \%$. Kadam and colleagues ${ }^{33}$ found that the perioperative use of dexmedetomidine lowered the incidence of postoperative JET from $23 \%$ to $9 \%$.

\section{Summary}

As many as one third of patients experience postoperative arrhythmias, of which JET and AT account for more than two thirds of the arrhythmias after CHS. Use of intraoperative $\mathrm{Mg}$ is associated with a reduction in the occurrence rate of multiple postoperative arrhythmias, especially JET and AT. Our results do not provide evidence that a greater dose (25 vs $50 \mathrm{mg} / \mathrm{kg}$ ) of Mg is associated with greater arrhythmia risk reduction. Despite the use of $\mathrm{Mg}$, there continued to be a high residual incidence of postoperative arrhythmias (Video 1).

\section{Study Limitations}

Our study is not based on a randomized trial design that potentially controls for the influence of confounding variables but rather a PSM cohort aimed at balancing measured baseline covariates that could influence the likelihood of postoperative arrhythmias. It represents an historical prospective review of one of the largest cohorts of children undergoing open-heart surgery for a diverse set of congenital heart defects and surgical procedure types. Small absolute standardized mean differences between the control and $\mathrm{Mg}$ populations indicated excellent quality of the propensity matching in balancing treatment groups and thus allowed objective comparisons of postoperative arrhythmias. Nevertheless, our observational (nonrandomized) study design limits the ability to draw firm causal inferences from these results.

Other limitations include the possibility of undetected arrhythmias, as this may have falsely decreased the frequency of arrhythmia events. The possibility exists that some wide complex arrhythmias may be atrial in origin

\section{Jeffrey P. Moak, MD}

Lower Risk of Postoperative Arrhythmias in Congenital Heart Surgery Following Intraoperative Administration of Magnesium

VIDEO 1. Text and verbal summary of the manuscript "Lower Risk of Postoperative Arrhythmias in Congenital Heart Surgery Following Intraoperative Administration of Magnesium." Video available at: https://www. jtcvs.org/article/S0022-5223(18)31027-4/fulltext. 
with bundle branch block or aberrancy and not necessarily ventricular in origin. There may be an era effect of CICU management that played a role in the development of postoperative arrhythmias. Over this period of time, differing approaches to the use of inotropes such as milrinone, dopamine, and epinephrine, which are known to facilitate the development of postoperative arrhythmias, may have contributed to changes in arrhythmia frequency and our results. However, the results of this study are useful in formulating hypotheses that can be tested in future prospective randomized clinical trials.

\section{References}

1. Rekawek J, Kansy A, Miszczaj-Knecht M, Manowska M, Bieganowska K, Brzezinska-Paszke M, et al. Risk factors for cardiac arrhythmias in children with congenital heart disease after surgical intervention in the early postoperative period. J Thorac Cardiovasc Surg. 2007;133:900-4.

2. Hoffman TM, Bush DM, Wernovsky G, Cohen MI, Wieand TS, Gaynor JW, et al. Postoperative junctional ectopic tachycardia in children: incidence, risk factors, and treatment. Ann Thorac Surg. 2002;74:1607-11.

3. Dodge-Khatami A, Miller OI, Anderson RH, Goldman AP, Gil-Jaurena JM, Elliott MJ, et al. Surgical substrates of postoperative junctional ectopic tachycardia in congenital heart defects. J Thorac Cardovasc Surg. 2002;123:624-30.

4. Pfammatter JP, Wagner B, Berdat P, Bachmann DC, Pavlovic M, Pfenninger J, et al. Procedural factors associated with early post-operative arrhythmias after repair of congenital heart disease. J Thorac Cardiovasc Surg. 2002;123:258-562.

5. Cecchin F, Johnsrude CL, Perry JC, Friedman RA. Effect of age and surgical technique on symptomatic arrhythmias after the Fontan procedure. Am J Cardiol. 1995;76:386-91.

6. Moak JP, Arias P, Kaltman JR, Cheng Y, McCarter R, Hanumanthaiah S, et al. Postoperative junctional ectopic tachycardia: risk factors for occurrence in the modern surgical era. Pacing Clin Electrophysiol. 2013;36:1156-68.

7. Jian W, Su L, Yiwu L. The effects of magnesium prime solution on magnesium levels and potassium loss in open heart surgery. Anesth Analg. 2003;96:1617-20.

8. Manrique AM, Arroyo M, Lin Y, El Khoudary SR, Colvin E, Lichtenstein S, et al. Magnesium supplementation during cardiopulmonary bypass to prevent junctional ectopic tachycardia after pediatric cardiac surgery: a randomized controlled study. J Thorac Cardiovasc Surg. 2010;139:162-9.

9. Dittrich S, Germanakis J, Dähnert I, Stiller B, Dittrich H, Vogel M, et al. Randomized trial on the influence of continuous magnesium infusion on arrhythmias following cardiopulmonary bypass surgery for congenital heart disease. Intensive Care Med. 2003;29:1141-4.

10. Lee HY, Ghimire S, Kim EY. Magnesium supplementation reduces postoperative arrhythmias after cardiopulmonary bypass in pediatrics: a meta-analysis of randomized controlled trials. Pediatr Cardiol. 2013;34:1396-403.

11. Dorman BH, Sade RM, Burnette JS, Wiles HB, Pinosky ML, Reeves ST, et al. Magnesium supplementation in the prevention of arrhythmias in pediatric patients undergoing surgery for congenital heart defects. Am Heart J. 2000;139:522-8.

12. Verma YS, Chauhan S, Gharde P, Lakshmy R, Kiran U. Role of magnesium in the prevention of postoperative arrhythmias in neonates and infants undergoing arterial switch operation. Interact Cardiovasc Thorac Surg. 2010;11:573-6.

13. Fairley JL, Zhang H, Glassford NJ, Bellomo R. Magnesium status and magnesium therapy in cardiac surgery: a systematic review and meta-analysis focusing on arrhythmia prevention. J Critical Care. 2017;42:69-77.

14. He D, Sznycer-Taub N, Cheng Y, McCarter R, Jonas RA, Hanumanthaiah S, et al. Magnesium lowers the incidence of postoperative junctional ectopic tachycardia in congenital heart surgical patients: is there a relationship to surgical procedure complexity? Pediatr Cardiol. 2015;36:1179-85.

15. Austin PC. A comparison of 12 algorithms for matching on the propensity score. Stat Med. 2014;33:1057-69.
16. Austin PC. Balance diagnostics for comparing the distribution of baseline covariates between treatment groups in propensity-score matched samples. Stat Med. 2009;28:3083-107.

17. Delaney JW, Moltedo JM, Dziura JD, Kopf GS, Snyder CS. Early postoperative arrhythmias after pediatric cardiac surgery. J Thorac Cardiovasc Surg. 2006;131: 1296-300.

18. Talwar S, Patel K, Juneja R, Choudhary SK, Airan B. Early postoperative arrhythmias after pediatric cardiac surgery. Asian Cardiovasc Thorac Ann. 2015; 23:795-801.

19. Baker WL. Treating arrhythmias with adjunctive magnesium: identifying future research directions. Eur Heart J Cardiovasc Pharmacother. 2017;3: 108-17.

20. Salih M, Smer A, Charnigo R, Ayan M, Darrat YH, Traina M, et al. Colchicine for prevention of post-cardiac procedure atrial fibrillation: meta-analysis of randomized controlled trials. Int J Cardiol. 2017;243: 258-62.

21. Rasmussen HS, Suenson M, McNair P, Nørregård P, Balslev S. Magnesium infusion reduces the incidence of arrhythmias in acute myocardial infarction: a double-blind placebo-controlled study. Clin Cardiol. 1987; 10:351-6.

22. Sueta CA, Clarke SW, Dunlap SH, Jensen L, Blauwet MB, Koch G, et al. Effect of acute magnesium administration on the frequency of ventricular arrhythmia in patients with heart failure. Circulation. 1994;89:660-6.

23. Ho KM. Atrial tachyarrhythmia after cardiac surgery: role of magnesium infusion. Intensive Care Med. 1999;25:243.

24. Satur CM. Magnesium and cardiac surgery. Ann R Coll Surg Engl. 1997;79: 349-54.

25. Nurozzler F, Tokgozoglu L, Pasaoglu I, Böke E, Ersoy U, Bozer AY. Atrial fibrillation after coronary artery bypass surgery: predictors and role of $\mathrm{MgSO} 4$ replacement. J Card Surg. 1996;1:421-7.

26. Maesen B, Nijs J, Maessen J, Allessie M, Schotten U. Post-operative atrial fibrillation: a maze of mechanisms. Europace. 2012;14:159-74.

27. Gholipour Baradari A, Emami Zeydi A, Ghafari R, Aarabi M, Jafari M. A double-blind randomized clinical trial comparing different doses of magnesium in cardioplegic solution for prevention of atrial fibrillation after coronary artery bypass graft surgery. Cardiovasc Ther. 2016;34:276-82.

28. Mohammadzadeh A, Towfighi F, Jafari N. Effect of magnesium on arrhythmia incidence in patients undergoing coronary artery bypass grafting. ANZ J Surg. May 22, 2017 [Epub ahead of print].

29. Ayyildiz P, Kasar T, Ozturk E, Ozyilmaz I, Tanidir IC, Guzeltas A, et al. Evaluation of permanent or transient complete heart block after open heart surgery for congenital heart disease. Pacing Clin Electrophysiol. 2016;39: $160-5$.

30. Ridley JM, Cheng H, Harrison OJ, Jones SK, Smith GL, Hancox JC, et al. Spontaneous frequency of rabbit atrioventricular node myocytes depends on SR function. Cell Calcium. 2008;44:580-91.

31. Amrousy DE, Elshehaby W, Feky WE, Elshmaa NS. Safety and efficacy of prophylactic amiodarone in preventing early junctional ectopic tachycardia (JET) in children after cardiac surgery and determination of its risk factor. Pediatr Cardiol. 2016;37:734-9.

32. Mahmoud AB, Tantawy AE, Kouatli AA, Baslaim GM. Propranolol: a new indication for an old drug in preventing postoperative junctional ectopic tachycardia after surgical repair of tetralogy of Fallot. Interact Cardiovasc Thorac Surg. 2008; 7:184-7.

33. Kadam SV, Tailor KB, Kulkarni S, Mohanty SR, Joshi PV, Rao SG. Effect of dexmedetomidine on postoperative junctional ectopic tachycardia after complete surgical repair of tetralogy of Fallot: a prospective randomized controlled study. Ann Card Anaesth. 2015;18:323-8.

Key Words: magnesium, postoperative arrhythmias, congenital heart surgery, junctional ectopic tachycardia, atrial tachycardia, ventricular tachycardia, atrioventricular block 
TABLE E1. Baseline characteristics in prematched cohorts

\begin{tabular}{|c|c|c|c|c|c|}
\hline Variable & $\begin{array}{l}\text { No-Mg control group } \\
\qquad(\mathbf{n}=\mathbf{7 5 0})\end{array}$ & $\begin{array}{c}\text { Mg-25 mg/kg } \\
\quad(\mathrm{n}=338)\end{array}$ & $\begin{array}{l}\text { Mg-50 mg/kg } \\
\quad(n=783)\end{array}$ & $\begin{array}{l}P \text { value (control } \\
\text { vs } \mathrm{Mg}-25 \mathrm{mg} / \mathrm{kg} \text { ) }\end{array}$ & $\begin{array}{c}P \text { value (control vs } \\
\mathrm{Mg}-50 \mathrm{mg} / \mathrm{kg} \text { ) }\end{array}$ \\
\hline Age, mo & $5(1-18)$ & $6(2-32)$ & $8(4-41)$ & $<.001 *$ & $<.001 *$ \\
\hline Weight, kg & $5.5(3.7-9.8)$ & $6.4(4-12.1)$ & $7.3(4.4-14.5)$ & $<.001 *$ & $<.001 *$ \\
\hline BSA, $m^{2}$ & $0.31(0.23-0.46)$ & $0.34(0.25-0.55)$ & $0.37(0.26-0.61)$ & $<.001 *$ & $<.001 *$ \\
\hline Male sex, n (\%) & $406(54)$ & $177(52)$ & $411(53)$ & .589 & .519 \\
\hline Race, n (\%) & & & & .939 & .063 \\
\hline White & $329(44)$ & $146(43)$ & $335(43)$ & & \\
\hline African American & $210(28)$ & $102(30)$ & $236(30)$ & & \\
\hline Hispanic & $103(14)$ & $44(13)$ & $75(10)$ & & \\
\hline Asian & $32(4)$ & $12(4)$ & $20(3)$ & & \\
\hline Other & $76(10)$ & $34(10)$ & $117(14)$ & & \\
\hline Cardiac defect, n (\%) & & & & $.009 *$ & $<.001 *$ \\
\hline Conotruncal/VSD & $391(52)$ & $144(43)$ & $315(40)$ & & \\
\hline Single ventricle & $200(27)$ & $108(32)$ & $155(20)$ & & \\
\hline Atrial septal defect & $63(8)$ & $24(7)$ & $84(11)$ & & \\
\hline Outflow obstruction & $46(6)$ & $24(7)$ & $79(10)$ & & \\
\hline Miscellaneous/valve & $50(7)$ & $38(11)$ & $150(20)$ & & \\
\hline Aristotle score, n (\%) & & & & $.015^{*}$ & $.012 *$ \\
\hline 1 or 2 & $394(53)$ & $204(60)$ & $461(59)$ & & \\
\hline 3 or 4 & $356(47)$ & $134(40)$ & $322(41)$ & & \\
\hline Crossclamp time, min & $41(30-55)$ & $35(18-48)$ & $39(21-59)$ & $<.001 *$ & .051 \\
\hline $\mathrm{CPB}$ time, $\min$ & $84(67-109)$ & $83(65-107)$ & $86(67-120)$ & .438 & $.003 *$ \\
\hline Surgical time, $\min$ & $190(165-227)$ & $210(175-240)$ & $230(190-280)$ & $<.001 *$ & $<.001 *$ \\
\hline
\end{tabular}

Continuous data are represented by the median (interquartile range). $N o-M g$, No magnesium given; $M g-25,25 \mathrm{mg} / \mathrm{kg} ; M g-50,50 \mathrm{mg} / \mathrm{kg} ; B S A$, body surface area; $V S D$, ventricular septal defect; $C P B$, cardiopulmonary bypass. *Statistically significant imbalance. 